\title{
A New Prenylisoflavone from the Antifungal Extract of Leaves of Vatairea guianensis Aubl.
}

\author{
Ronilson F. Souza, ${ }^{*, a}$ Geilson A. da Silva, ${ }^{b}$ Alberto C. Arruda ${ }^{b}$ Milton N. da Silva, ${ }^{b}$ \\ Alberdan S. Santos, ${ }^{b}$ Daniella P. A. Grisólia, ${ }^{c}$ Moises B. Silva, ${ }^{c}$ Claudio G. Salgado ${ }^{c}$ and \\ Mara Silvia P. Arruda ${ }^{b}$ \\ ${ }^{a}$ Departamento de Ciências Naturais, Universidade do Estado do Pará, \\ 68860-000 Salvaterra-PA, Brazil

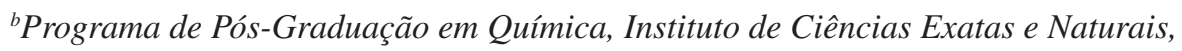 \\ Universidade Federal do Pará, 66075-970 Belém-PA, Brazil \\ ${ }^{c}$ Laboratório de Dermato-Imunologia UEPA/UFPA/MC (Universidade do Estado do Parál \\ Universidade Federal do Pará/Centro de Referência e Treinamento em Dermatologia Sanitária do \\ Estado do Pará "Dr. Marcello Candia”), 67200-000 Marituba-PA, Brazil
}

\begin{abstract}
A new compound, 5,7,3'-trihydroxy-4'-methoxy-8-prenylisoflavone, was isolated from the leaves of Vatairea guianensis Aubl. (Fabaceae), together with two known isoflavones lupiwighteone and 5,7,4'-trihydroxy-3'-methoxy-8-prenylisoflavone. All isolated compounds were characterized based on infrared (IR), UV, ${ }^{1} \mathrm{H}$ and ${ }^{13} \mathrm{C}$ nuclear magnetic resonance (NMR), including 2D NMR analyses and high resolution mass spectrometry. The ethanolic extract from $V$. guianensis leaves displayed activity against Candida dubliniensis, C. albicans and C. krusei. However, the EtOAc fraction from that extract exhibited more significant activity than the ethanolic extract, showing antifungal activity for all fungi species investigated. The major compound 5,7,3'-trihydroxy4'-methoxy-8-prenylisoflavone isolated from that EtOAc fraction was also active against C. parapsilosis and C. dubliniensis.
\end{abstract}

Keywords: antifungal activity, Vatairea guianensis, Fabaceae, 5,7,3'-trihydroxy-4'-methoxy8-prenylisoflavone

\section{Introduction}

Many plants from Brazilian biomes such as the Cerrado, Atlantic Forest and Amazon Forest have been used as natural medicines by local communities for treating tropical diseases such as fungal and bacterial infections. ${ }^{1,2}$ The population makes use of these traditional medicines through medical prescriptions, self-medication, home remedies and other means. ${ }^{3}$ Among them Vatairea guianensis Aubl. (Fabaceae), a plant native to the Amazon, popularly known as "fava de impingem" (ringworm bean) is used in folk medicine for treating mycoses. ${ }^{4,5}$

The genus Candida has at least 15 distinct species that cause human disease, such as $C$. kefyr, C. tropicalis, C. lusitaniae, C. dubliniensis, C. guilliermondii and C. rugosa, but the five most common pathogens are:

*e-mail: ronilson@uepa.br
C. glabrata, C. tropicalis, C. parapsilosis, C. krusei and the most common and well-studied of the disease-causing species in that genus is $C$. albicans. ${ }^{6}$ Candidiasis may present in forms ranging from superficial skin lesions ${ }^{7}$ to disseminated infections and in recent decades, there has been a substantial increase in the occurrence of invasive fungal infections (IFIs) caused by C. albicans, ${ }^{8}$ which can naturally colonize the skin, genital, and/or intestinal mucosa in up to $70 \%$ of healthy individuals ${ }^{9}$ and is the most common bloodstream pathogen in the USA, responsible for $50 \%$ of the cases. ${ }^{6}$

In invasive candidiasis, echinocandin plays a central role in the treatment, but there has recently been an increased incidence of resistant strains in both nosocomial and in community fungal infections. ${ }^{10}$ Despite the large number of antifungal medicines available on the market, aside from their side effects, drug resistance is an obstacle in treating. An important resistant phenotype in Candida is 
azole resistance and of greatest concern is the evolution of multidrug-resistant organisms refractory to several different classes of antifungal agents, especially among common Candida species. ${ }^{11}$

Given the increasing occurrence of fungal infections in humans along with increasing resistance to available medicines, it is important to identify new antifungal compounds that will enable development of new medicines. ${ }^{12}$

Previous phytochemical investigations involving various parts of $V$. guianensis have shown compounds belonging to the anthraquinone, triterpene and isoflavone classes. ${ }^{13-16}$ The present paper reports the isolation and structural characterization by spectroscopic and spectrometric methods of a new compound, named 5,7,3'-trihydroxy4'-methoxy-8-prenylisoflavone (3), along with other two known isoflavones lupiwighteone (1) and 5,7,4'-trihydroxy3'-methoxy-8-prenylisoflavone (2) (Figure 1). The ethanolic extract, hexanic, EtOAc and $\mathrm{MeOH} / \mathrm{H}_{2} \mathrm{O}$ fractions and compounds $\mathbf{1}$ and $\mathbf{3}$ were evaluated for their antifungal activities against certain pathogenic fungi but, due to insufficient quantities, the antifungal testing of compound 2 was not carried out.

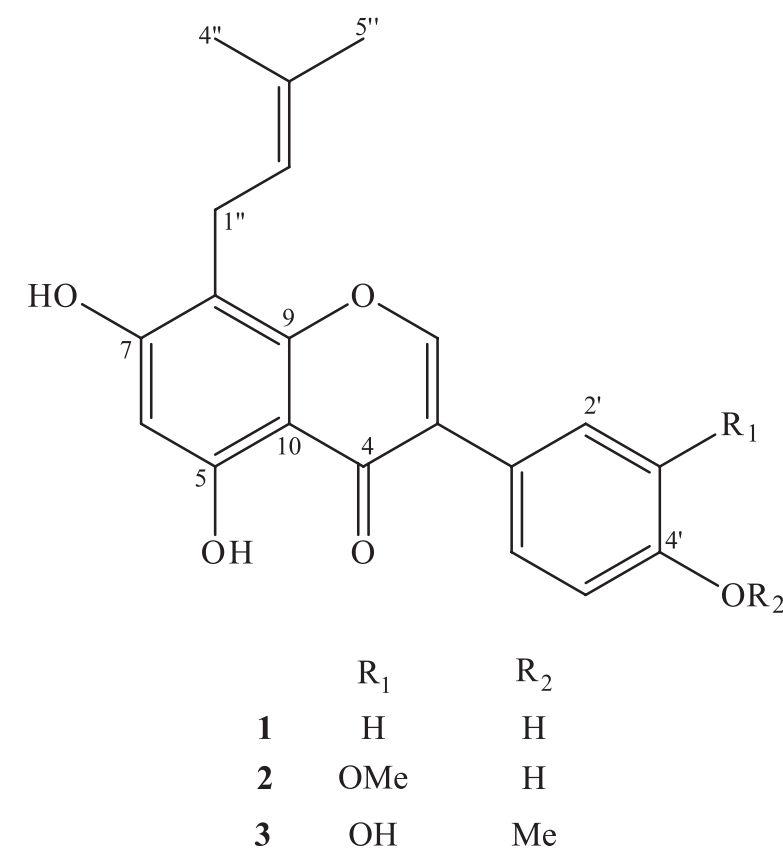

Figure 1. Chemical structures of isoflavones 1-3 isolated from the leaves of $V$. guianensis.

\section{Experimental}

\section{General experimental procedures}

The melting point (mp) was determined on a Quimis Q340S23 melting point analyzer. UV spectra were obtained from HPLC equipped with DAD Prominence SPDM-20A
(Shimadzu, Tokyo, Japan). Infrared (IR) spectra were recorded on a Shimadzu Corporation IR Prestige 21 spectrometer (Tokyo, Japan) with KBr pellets. Nuclear magnetic resonance (NMR) spectra, including 1D and 2D experiments (see Supplementary Information), were recorded on a Varian Mercury-300 spectrometer (Palo Alto, CA, USA), operating at $300 \mathrm{MHz}$ at ${ }^{1} \mathrm{H}$ and $75 \mathrm{MHz}$ at ${ }^{13} \mathrm{C}$, using acetone- $d_{6}, \mathrm{CD}_{3} \mathrm{OD}$ or a mixture $\left(\mathrm{CDCl}_{3}\right.$ and a few drops $\left.\mathrm{CD}_{3} \mathrm{OD}\right)$ as deuterosolvents $(0.6 \mathrm{~mL})$. Mass spectrometry (MS) analysis was performed on a XEVO G2-SQ-TOF mass spectrometer (Waters Corp., Milford, MA, USA) equipped with a lockspray source where an internal reference compound (leucine-enkephalin) was introduced simultaneously with the analyte for accurate mass measurements. Electrospray mass spectra data were recorded in a positive ionization mode for a mass range from $\mathrm{m} / \mathrm{z} 50$ to 1000 with a scan time of $0.1 \mathrm{~s}$. The source temperature was set to $150^{\circ} \mathrm{C}$ with a cone gas flow of $20 \mathrm{~L} \mathrm{~h}^{-1}$. The desolvation gas flow was set to $600 \mathrm{~L} \mathrm{~h}^{-1}$ at a temperature of $250{ }^{\circ} \mathrm{C}$. The capillary was set at $3.5 \mathrm{kV}$ with cone voltage at $20 \mathrm{~V}$. MassLynx software (Waters, Milford, MA, USA) was used for system control and data acquisition. High-performance liquid chromatography (HPLC) was carried out in a semi-preparative LC-8A Shimadzu system with a SPD-10AV Shimadzu UV detector (Tokyo, Japan), using a Phenomenex Gemini C18 column $(250 \times 10 \mathrm{~mm}, 5 \mu \mathrm{m})$, isocratic system of $50 \%$ acetonitrile-water and a flow rate of $4.7 \mathrm{~mL} \mathrm{~min}^{-1}$. Detection was performed at 254 and $282 \mathrm{~nm}$. All solvents were filtered through a $0.45 \mathrm{~mm}$ nylon membrane filter prior to analysis. Open column chromatography was run using silica gel 60 (70-230 Mesh, Macherey-Nagel, Düren, Germany). Thin layer chromatography (TLC) was performed on precoated silica gel aluminium sheets (Macherey-Nagel, Düren, Germany) by detection with a spraying reagent (vanillin/sulfuric acid/EtOH solution) followed by heating at $100{ }^{\circ} \mathrm{C}$ and with NP-PEG reagent (diphenylborinic acid aminoethyl ester-polyethylene glycol) for flavonoid detection.

\section{Plant material}

Leaves of $V$. guianensis were collected in November 2010 in the city of Belém, state of Pará, Brazil. Identification was performed by Manoel R. Cordeiro from Embrapa Amazônia Oriental, Pará, Brazil, and a voucher specimen (IAN - 187050) has been deposited in the herbarium at Embrapa Amazônia Oriental.

\section{Extractions and isolation}

Obtaining the ethanol extract from leaves of $V$. guianensis and fractionating it were carried out according 
to procedures reported by Souza et al. ${ }^{13}$ Briefly, dried and powdered leaves $(1.0 \mathrm{~kg})$ were subjected to extraction with ethanol by maceration at room temperature. The solvent was removed under vacuum, furnishing a residue $(180.0 \mathrm{~g})$. The crude ethanol residue $(50.0 \mathrm{~g})$ was dissolved in $500 \mathrm{~mL}$ $\mathrm{MeOH} / \mathrm{H}_{2} \mathrm{O}$ mixture $(9: 1)$, then partitioned three times with hexane $(3 \times 500 \mathrm{~mL})$, ethyl acetate $(3 \times 500 \mathrm{~mL})$ and the remaining hydroalcoholic phase. The solutions obtained were dried to provide three fractions: a hexane fraction (7.5 g), an EtOAc fraction (22.0 g) and a remaining $\mathrm{MeOH} / \mathrm{H}_{2} \mathrm{O}$ fraction $(20.0 \mathrm{~g}$ ). The EtOAc fraction (10.0 g) was subjected to silica gel column chromatography with gradient elution of hexane-EtOAc (9:1, 1:1 and 0:10) and EtOAc-MeOH (9:1, 8:2 and 0:10), to obtain six fractions (Fr.1-Fr.6), respectively. The Fr-2 fraction (1.0 g) eluted with hexane:EtOAc (1:1) was sonicated in $4.8 \mathrm{~mL}$ of acetonitrile for $1 \mathrm{~min}$. Next, $1.2 \mathrm{~mL}$ of $\mathrm{H}_{2} \mathrm{O}$ was added and sonicated again for $1 \mathrm{~min}$. The solution was subjected to solid phase extraction (SPE) in a C18 cartridge (Phenomenex, $1 \mathrm{~g}$ of stationary phase / $6 \mathrm{~mL}$ ). After evaporation, the residue (about $100 \mathrm{mg}$ ) was submitted to semi-preparative reversed phase HPLC $(250 \times 10 \mathrm{~mm}$ Phenomenex Gemini C18, $50 \%$ acetonitrile-water, flow rate $4.7 \mathrm{~mL} \mathrm{~min}^{-1}, 254 \mathrm{~nm}$ ) to yield $\mathbf{1}(10 \mathrm{mg}), \mathbf{2}(3 \mathrm{mg})$ and $\mathbf{3}(9 \mathrm{mg})$, which showed chromatographic peak retention times of 17.3, 18.8 and $20.0 \mathrm{~min}$, respectively. These compounds were identified by NMR and mass spectrometry methods, and by comparison with available reported data.

\section{5,7,3'-Trihydroxy-4'-methoxy-8-prenyl-isoflavone (3)}

Pale yellow solid; soluble in the solvents: acetone, ethyl acetate, methanol, pyridine and DMSO; mp $110-113{ }^{\circ} \mathrm{C}$; UV $\lambda / \mathrm{nm}$ (acetonitrile-water) 239, 265; IR (KBr) $\nu_{\max } / \mathrm{cm}^{-1} 3363,2966,1656,1514,1425,1273,1037,837$; ${ }^{1} \mathrm{H}$ and ${ }^{13} \mathrm{C}$ NMR spectral data, see Table 1; HRESITOF-MS (electrospray ionization-high resolution time-of-flight mass spectrometry) $\mathrm{m} / z 369.1352[\mathrm{M}+\mathrm{H}]^{+}$(calcd. for $[\mathrm{M}+\mathrm{H}]^{+}$, $\mathrm{C}_{21} \mathrm{H}_{20} \mathrm{O}_{6}+\mathrm{H}^{+}, 369.1338$ ).

\section{In vitro antifungal activity}

The minimal inhibitory concentrations (MICs) were determined by broth microdilution methods based on the Clinical and Laboratory Standards Institute (CLSI) reference protocol M38-A2. ${ }^{17}$ All the test strains were subcultured on Sabouraud dextrose agar (SDA) (Sigma-Aldrich, Saint Louis, MO, USA), incubated for 24-72 hours at temperature $30{ }^{\circ} \mathrm{C}$, and their inocula were prepared according to procedures reported by Daboit et al. ${ }^{18}$ That involved scraping across the surface of the fungal colonies with a sterile pipette and sterile saline solution $(0.85 \%)$,
Table 1. The ${ }^{1} \mathrm{H}$ and ${ }^{13} \mathrm{C}$ NMR chemical shifts $\left(\delta_{\mathrm{H}}\right.$ in ppm) and HMBC correlations of compound 3 in $\mathrm{CDCl}_{3}$ and a few drops of $\mathrm{CD}_{3} \mathrm{OD}^{\mathrm{a}}$

\begin{tabular}{|c|c|c|c|}
\hline \multirow{2}{*}{ Position } & \multicolumn{3}{|c|}{3} \\
\hline & $\delta_{\mathrm{H}}$ & $\delta_{\mathrm{C}}$ & ${ }^{\mathrm{b}} \mathrm{HMBC}{ }^{2,3} J_{\mathrm{C}, \mathrm{H}}$ \\
\hline 2 & $7.85(\mathrm{~s})$ & 152.9 & C-3, C-4, C-9, C-1' \\
\hline 3 & & 122.7 & \\
\hline 4 & & 180.9 & \\
\hline 5 & & 159.4 & \\
\hline 6 & $6.24(\mathrm{~s})$ & 98.6 & C-5, C-7, C-8, C-10 \\
\hline 7 & & 161.5 & \\
\hline 8 & & 106.7 & \\
\hline 9 & & 155.2 & \\
\hline 10 & & 105.1 & \\
\hline 1 ' & & 123.6 & \\
\hline $2^{\prime}$ & $6.99(\mathrm{~d}, J 1.9 \mathrm{~Hz})$ & 115.5 & C-3, C-3', C-4', C-6' \\
\hline $3^{\prime}$ & & 145.5 & \\
\hline $4^{\prime}$ & & 147.2 & \\
\hline 5 , & $6.84(\mathrm{~d}, J 8.4 \mathrm{~Hz})$ & 111.0 & C-1', C-3', C-4' \\
\hline $6^{\prime}$ & $6.93(\mathrm{dd}, J 1.9,8.4 \mathrm{~Hz})$ & 120.5 & $\mathrm{C}-3, \mathrm{C}-2^{\prime}, \mathrm{C}-4^{\prime}$ \\
\hline $1 "$ & $3.35(\mathrm{~d}, J 6.7 \mathrm{~Hz})$ & 21.1 & $\mathrm{C}-7, \mathrm{C}-8, \mathrm{C}-9, \mathrm{C}-2$ ", C-3" \\
\hline $2 "$ & $5.15(\mathrm{brt}, J 6.7 \mathrm{~Hz})$ & 121.8 & C- 8 \\
\hline $3 "$ & & 131.8 & \\
\hline $4 "$ & $1.62(\mathrm{~s})$ & 25.4 & $\mathrm{C}-2 ", \mathrm{C}-3 "$ \\
\hline $5 "$ & $1.73(\mathrm{~s})$ & 17.4 & C-2", C-3" \\
\hline OMe-4' & $3.83(\mathrm{~s})$ & 55.6 & C-4' \\
\hline
\end{tabular}

${ }^{a} \mathrm{H}$ and ${ }^{13} \mathrm{C}$ NMR data were recorded at 300 and $75 \mathrm{MHz}$, respectively. Multiplicity and coupling constants $(\mathrm{J}$ in $\mathrm{Hz}$ ) are in parentheses. Number of hydrogen atoms bound to carbon atoms deduced by comparative analysis of ${ }^{1} \mathrm{H}$ and DEPT ${ }^{13} \mathrm{C}$ NMR and HETCOR spectra; ${ }^{16} \mathrm{H}^{-13} \mathrm{C}$ HMBC correlations are from the carbon atoms specified to the protons indicated.

containing $0.05 \%$ Tween 40 . After standing for 3-5 min, at room temperature for deposition of larger particles, the concentration of spores in the supernatant was adjusted spectrophotometrically $(530 \mathrm{~nm})$ to a per cent transmission in the 80-82 range for Candida albicans (INGOS 40175), Candida krusei (ATCC 6258), Candida parapsilosis (ATCC 22019) and Candida dubliniensis (CBS 7987). These suspensions were diluted to 1:50 in a synthetic RPMI-1640 medium buffered with morpholinopropanisulfonic acid (MOPS; Sigma ${ }^{\circledR}$, Saint Louis, MO, USA).

The extracts, fractions and pure compounds were primarily dissolved in dimethyl sulfoxide (DMSO) and diluted in sodium bicarbonate-free RPMI 1640 medium (Sigma ${ }^{\circledR}$, Saint Louis, MO, USA) buffered with $165 \mathrm{mmol} \mathrm{L}^{-1}$ MOPS, pH 7.0, and supplemented with $4 \mathrm{mmol} \mathrm{L}{ }^{-1} \mathrm{~L}$-glutamine. The final DMSO concentration was maintained as less than $1 \%$. Concentrations ranged 
from 1024 to $0.125 \mu \mathrm{g} \mathrm{mL}-1$ for extracts and fractions; for pure compounds they ranged from 256 to $0.125 \mu \mathrm{g} \mathrm{mL}^{-1}$, and the assay was carried out as reported previously. ${ }^{19}$ The MIC was determined as the lowest concentration of the crude extract, fractions and the pure compound that inhibited the complete growth of the organisms.

Minimum fungicidal concentrations (MFCs) were established following the incubation time determined for the MIC. Thirty $\mu \mathrm{L}$ from each well with complete growth inhibition were inoculated onto SDA plates and incubated at $30{ }^{\circ} \mathrm{C}$ for up to $72 \mathrm{~h}$. The MFC was defined as the lowest concentration of the extracts, fractions and pure compounds, in which there was either no growth or a growth up to seven colonies, which corresponds to a $99.9 \%$ kill; ${ }^{20}$ fluconazole was used as the standard antibiotic. All experiments were conducted in triplicate.

\section{Results and Discussion}

Compound $\mathbf{1}$ was identified as lupiwighteone by comparing its spectral data with those reported in literature. ${ }^{21,22}$ This substance is being reported for the first time for the genus Vatairea and presents important antiinflammatory activity according to Paoletti et al. ${ }^{23}$ as well as being considered a very potent phytoestrogen. ${ }^{24}$

Compound 2 was identified as 5,7,4'-trihydroxy3'-methoxy-8-prenylisoflavone. This substance has been reported only once for the plant Wyethia mollis,${ }^{25}$ however, the data from HRESITOF-MS, ${ }^{1} \mathrm{H}$ and ${ }^{13} \mathrm{C}$ NMR are being reported for the first time in this paper.

Compound $\mathbf{3}$ was obtained as a pale yellow solid, with the molecular formula $\mathrm{C}_{21} \mathrm{H}_{20} \mathrm{O}_{6}$, based on the $[\mathrm{M}+\mathrm{H}]^{+}$ peak at $m / z 369.1352$ (calcd. for $[\mathrm{M}+\mathrm{H}]^{+}, \mathrm{C}_{21} \mathrm{H}_{20} \mathrm{O}_{6}+\mathrm{H}^{+}$, 369.1338) in the HRESITOF-MS, and confirmed by ${ }^{1} \mathrm{H}$ and ${ }^{13} \mathrm{C}$ NMR experiments (Table 1). The ${ }^{1} \mathrm{H}$ NMR signal at $\delta_{\mathrm{H}-2} 7.85$ and ${ }^{13} \mathrm{C}$ NMR signals at $\delta_{\mathrm{C}-2} 152.9, \delta_{\mathrm{C}-3} 122.7$ and $\delta_{\mathrm{C}-4} 180.9$, were typical of isoflavones. ${ }^{26}$ Additionally, the ${ }^{1} \mathrm{H}$ NMR spectrum exhibited signals in the aromatic region at $\delta_{\mathrm{H}} 6.84(1 \mathrm{H}, \mathrm{d}, J 8.4 \mathrm{~Hz}), 6.93(1 \mathrm{H}, \mathrm{dd}, J 1.9$ and $8.4 \mathrm{~Hz})$ and $6.99(1 \mathrm{H}, \mathrm{d}, J 1.9 \mathrm{~Hz})$, which indicated an ABX spin system of a 1,3,4-trisubstituted phenyl group, as well as one singlet at $\delta_{\mathrm{H}} 6.24$ assigned to a pentasubstituted benzene ring. The signal singlet at $\delta_{\mathrm{H}} 3.83$ indicated the presence of an OMe group connected to an aromatic ring. All couplings were confirmed through analysis of the ${ }^{1} \mathrm{H}-{ }^{-} \mathrm{H}$ correlation spectroscopy (COSY) spectrum. Besides the signals related to $\mathrm{C}$-ring carbons, the ${ }^{13} \mathrm{C} \mathrm{NMR}$ spectrum of $\mathbf{3}$ exhibited another 21 signals attributed to twentyone carbons with the aid of the heteronuclear correlation spectroscopy (HETCOR) and heteronuclear multiple bond correlation (HMBC) experiments.

The C-prenyl group $\left[\delta_{\mathrm{H}} 3.35\right.$ (d, J $6.7 \mathrm{~Hz}, \mathrm{H}-1$ "), 5.15 (brt, J 6.7 Hz, H-2"), 1.62 (s, Me-4") and 1.73 (s, Me-5")] was confirmed as attached at C-8 by the ${ }^{3} J_{\mathrm{C}, \mathrm{H}}$ correlations in the HMBC experiments (Table 1) between the signals at $\delta_{\mathrm{H}} 7.85(\mathrm{H}-2)$ and $3.35(\mathrm{H}-1$ ") with the signal at $\delta_{\mathrm{C}} 155.2(\mathrm{C}-9)$. The location of the $\mathrm{OH}$ and $\mathrm{OMe}$ groups at C-3' and C-4' of the B-ring, respectively, was sustained by combining the HMBC cross-peaks from H-6' $\left(\delta_{\mathrm{H}} 6.93\right)$ and $\mathrm{OMe}\left(\delta_{\mathrm{H}} 3.83\right)$ to $\mathrm{C}-4$ ' $\left(\delta_{\mathrm{C}} 147.2\right)$ with the nuclear Overhauser effect (NOE) observed in the NOE difference spectra, which revealed spatial interactions between H-5' and OMe-4'. Therefore, 3 was characterized as 5,7,3'-trihydroxy-4'-methoxy-8-prenylisoflavone. This compound is a new natural product.

In evaluating the inhibition of fungal growth by $V$. guianensis, the extracts that presented MICs $\leq 800 \mu \mathrm{g} \mathrm{mL}^{-1}$ and the pure compounds with MICs $\leq 250 \mu \mathrm{g} \mathrm{mL}^{-1}$ were defined as active, these values being based on the work of Stein et al. ${ }^{27}$ The results of the MICs obtained in this study are shown in Table 2.

The most significant result of the minimum inhibitory concentration for the EtOH extract from leaves was $32 \mu \mathrm{g} \mathrm{mL}{ }^{-1}$ for $C$. dubliniensis. For the strains of fungi

Table 2. Minimal inhibitory concentration (MIC) and minimum fungicidal concentration (MFC) of crude extract, fractions and constituents isolated from V. guianensis against pathogenic microorganisms

\begin{tabular}{lcccc}
\hline \multirow{2}{*}{ Sample } & \multicolumn{3}{c}{ MIC $(\mathrm{MFC}) /\left(\mu \mathrm{gL}^{-1}\right)$} \\
\cline { 2 - 5 } EtOH extract & C. parapsilosis & C. albicans & C. krusei & C. dubliniensis \\
Hexanic fraction & $>1024(-)$ & $128(512)$ & $128(-)$ & $32(1024)$ \\
EtOAc fraction & $64(-)$ & $1024(1024)$ & $512(512)$ & $64(-)$ \\
$\mathrm{MeOH} / \mathrm{H}_{2} \mathrm{O}$ fraction & $8(32)$ & $16(32)$ & $8(32)$ & $8(16)$ \\
$\mathbf{1}$ & $>1024(-)$ & $1024(-)$ & $1024(-)$ & $1024(-)$ \\
$\mathbf{3}$ & $>256(-)$ & $>256(-)$ & $>256(-)$ & $32(-)$ \\
Fluconazole & $32(-)$ & $>256(-)$ & $>256(-)$ & $8(-)$ \\
\hline
\end{tabular}

-: Not detected in the assay conditions. 
C. albicans and C. krusei the EtOH extract was also active showing MIC of $128 \mu \mathrm{g} \mathrm{mL} \mathrm{m}^{-1}$, although it was inactive for C. parapsilosis (MIC > $1024 \mu \mathrm{g} \mathrm{mL} \mathrm{m}^{-1}$ ) (Table 2).

The EtOAc fraction showed promising fungicide activity against all fungi, with MIC values in the range of $8-16 \mu \mathrm{gL}^{-1}$ and MFC with values in the range of $16-32 \mu \mathrm{g} \mathrm{mL}^{-1}$ (Table 2). The major compound (3) showed fungistatic activity against C. parapsilosis ( $\mathrm{MIC}=32 \mu \mathrm{g} \mathrm{mL}-1$ ) and a more significant result against $C$. dubliniensis (MIC $=8 \mu \mathrm{g} \mathrm{mL}^{-1}$ ), whereas the compound lupiwighteone (1) was active only against C. dubliniensis ( $\mathrm{MIC}=32 \mu \mathrm{g} \mathrm{\textrm {mL } ^ { - 1 }}$ ).

\section{Conclusions}

Phytochemical investigation of the antifungal fraction (EtOAc) from $V$. guianensis leaves resulted in the isolation of a new isoflavone (3) besides other two known isoflavones. These compounds are in agreement with the typical chemical profile of plants of the Vatairea genus and Fabaceae family. The results of evaluating the antifungal activity of $V$. guianensis indicate the potential of this species, but it is necessary to expand the studies to provide scientific support to popular use of this plant in the treatment of skin infections caused by fungi.

\section{Supplementary Information}

Supplementary information, including ${ }^{1} \mathrm{H}$ and ${ }^{13} \mathrm{C}$ NMR, DEPT, COSY, HETCOR, and HMBC spectra, as well as mass spectra (Figures S1-S9), is available free of charge at http://jbcs.sbq.org.br as a PDF file.

\section{Acknowledgments}

The authors are grateful to Coordenação de Aperfeiçoamento de Pessoal de Nível Superior (CAPES), to CAPES PROAMAZONIA, and to Conselho Nacional de Desenvolvimento Científico e Tecnológico (CNPq) for financial support.

\section{References}

1. Alves, T. M. A.; Silva, A. F.; Brandão, M.; Grandi, T. S. M.; Smânia, E. F.; Smânia Jr., A.; Zani, C. L.; Mem. Inst. Oswaldo Cruz 2000, 9, 367.

2. Duarte, M. C. T.; Figueira, G. M.; Sartoratto, A.; Rehder, V. L. G.; Delarmelina, C.; J. Ethnopharmacol. 2005, 97, 305.

3. Robinson, M. M.; Zhang, X.; http://www.who.int/medicines/ areas/policy/world_medicines_situation/en/, accessed in August 2016.

4. Lima, H. C.; Arq. Jard. Bot. Rio de Janeiro 1982, 26, 173.
5. Santos, J. F. L.; Pagani, E.; Ramos, J.; Rodrigues, E.; J. Ethnopharmacol. 2012, 142, 503.

6. McCarty, T. P.; Pappas, P. G.; Infect. Dis. Clin. North Am. 2016, 30, 124.

7. Kashem, S. W.; Kaplan, D. H.; Trends Immunol. 2016, 37, 440.

8. Garey, K. W.; Aitken, S. L.; Dima-Ala, A.; Beyda, N. D.; Kuper, K.; Xie, Y.; Koo, H. L.; Am. J. Med. Sci. 2015, 349, 320.

9. Perlroth, J.; Choi, B.; Spellberg, B.; Med. Mycol. 2007, 45, 346.

10. Miyazaki, T.; Kohno, S.; Expert Rev. Anti-Infect. Ther. 2015 , 13, 1183 .

11. Cowen, L. E.; Sanglard, D.; Howard, S. J.; Rogers, P. D.; Perlin, D. S.; Cold Spring Harb. Perspect. Med. 2015, 5, a019752.

12. Mahlo, S. M.; McGaw, L. J.; Eloff, J. N.; Crop. Prot. 2010, 29 , 1529.

13. Souza, R. F.; Marinho, V. H. S.; Silva, G. A.; Costa-Jr, L. M.; Silva, J. K. R.; Bastos, G. N. T.; Arruda, A. C.; Silva, M. N.; Arruda, M. S. P.; J. Braz. Chem. Soc. 2013, 24, 1857.

14. Souza, R. F.; Silva, J. K. R.; Silva, G. A.; Arruda, A. C.; Silva, M. N.; Arruda, M. S. P.; Rev. Virtual Quim. 2015, 7, 1893.

15. Piedade, L. R.; Wolter Filho, W.; Acta Amaz. 1988, 18, 185.

16. Ottobelli, I.; Facundo, V. A.; Zuliani, J.; Luz, C. C.; Brasil, H. O. B.; Militão, J. S. L. T.; Braz-Filho, R.; Acta Amaz. 2011, 3, 393.

17. CLSI Document M38-A2; Reference Method for Broth Dilution Antifungal Susceptibility Testing of Filamentous Fungi. Approved Standard, $3^{\text {rd }}$ ed.; Clinical and Laboratory Standards Institute: Wayne, Pennsylvania, USA, 2008.

18. Daboit, T. C.; Magagnin, C. M.; Heidrich, D.; Antochevis, L. C.; Vigolo, S.; Meirelles, L. C.; Alves, K.; Scroferneker, M. L.; Mycoses 2014, 57, 116.

19. Mahlo, S. M.; McGaw, L. J.; Eloff, J. N.; J. Ethnopharmacol. 2013, 148, 909.

20. Pfaller, M. A.; Sheehan, D. J.; Rex, J. H.; Clin. Microbiol. Rev. 2004, 17, 280.

21. Al-Maharik, N.; Botting, N. P.; Tetrahedron 2003, 59, 4177.

22. Hashidoko, Y.; Tahara, S.; Mizutani, J.; Agric. Biol. Chem. 1986, 50, 1797.

23. Paoletti, T.; Fallarini, S.; Gugliesi, F.; Minassi, A.; Appendino, G.; Lombardi, G.; Eur. J. Pharmacol. 2009, 620, 120.

24. Wätjen, W.; Weber, N.; Lou, Y. J.; Wang, Z. Q.; Chovolou, Y.; Kampkötter, A.; Kahl, R.; Proksch, P.; Food Chem. Toxicol. 2007, 45, 119.

25. Bohm, B. A.; Choy, J. B.; Lee, A. Y. M.; Phytochemistry 1989, $28,501$.

26. Bandeira, P. N.; Farias, S. S.; Lemos, T. L. G.; Braz-Filho, R.; Santos, H. S.; Albuquerque, M. R. J. R.; Costa, S. M. O.; J. Braz. Chem. Soc. 2011, 22, 372.

27. Stein, A. C.; Alvarez, S.; Avancini, C.; Zacchino, S.; Poser, G. V.; J. Ethnopharmacol. 2006, 107, 95.

Submitted: June 13, 2016 Published online: September 1, 2016 